\title{
Castleman's Disease Clinical Case and Literature Review
}

\author{
Youness Khdach $^{1}$, Mounir Jamali ${ }^{1 *}$, Mohamed Alami ${ }^{2}$, Ahmed Ameur ${ }^{3}$, Elias Andrea ${ }^{4}$, Raymond Andary ${ }^{5}$
}

\author{
${ }^{1}$ Resident in the Urology Department of the Med V Military Hospital of Rabat, Rabat, Morocco \\ ${ }^{2} \mathrm{Head}$ of Urology Department of the Med V Military Hospital of Rabat, Rabat, Morocco \\ ${ }^{3}$ Uro-Nephrology Pole Leader of the Med V Military Hospital of Rabat, Rabat, Morocco \\ ${ }^{4}$ Urologist in Compiègne-Noyon Hospital Center, ZAC de Mercières 3, 8 Avenue Henri Adnot, 60200 Compiègne, France \\ ${ }^{5}$ Head of Urology Department in Compiègne-Noyon Hospital Center, ZAC de Mercières 3, 8 Avenue Henri Adnot, 60200 Compiègne, France
}

DOI: $10.36347 /$ sjmcr.2021.v09i01.005

| Received: 27.09.2020 | Accepted: 12.10.2020 | Published: 11.02.2021

*Corresponding author: Jamali Mounir

\section{Abstract}

Castleman's disease or angiofollicular lymphoid hyperplasia is a rare condition of uncertain cause. It poses a diagnostic and therapeutic problem. We report the clinical case of a 58-year-old patient who presents LUTS associated with microscopic hematuria with an abdominopelvic CT scan in favor of a $20 \mathrm{~mm}$ retroperitoneal tissue lesion at the lower pole of the right kidney which is enhanced by injection of PC posing a differential diagnosis problem with the other retroperitoneal masses. The biopsy under scanner was not performed given the difficult localization of the lesion, it was finally lumpectomy with pathological study that made it possible to make the diagnosis. The immediate and remote post-operative consequences were favorable. Through this clinical case and through a literature review, we analyze the epidemiological, diagnostic and therapeutic aspects of this rare pathology.

Keywords: angiofollicular lymphoid hyperplasia, CT scan, retroperitoneal tissue, scanner.

Copyright $\odot 2021$ The Author(s): This is an open-access article distributed under the terms of the Creative Commons Attribution 4.0 International License (CC BY-NC 4.0) which permits unrestricted use, distribution, and reproduction in any medium for non-commercial use provided the original author and source are credited.

\section{INTRODUCTION}

Castleman's disease or angiofollicular lymphoid hyperplasia is a rare condition of uncertain cause. It poses a diagnostic and therapeutic problem. In fact, there are two clinical forms: localized unicentric form, pseudotumoral with a good prognosis; and multicentric form associated with more aggressive dysimmunity manifestations [1, 2]. Three histological types have been identified: the type with hyalinized vascularization, the plasma cell type and an intermediate mixed type.

In this article, we report on Castleman's disease localized in a 58-year-old patient and analyze, through a review of the literature, the epidemiological, diagnostic and therapeutic aspects of this rare pathology.

\section{Patient and Observation}

Male DO, 58 years old, history of intestinal obstruction at 14 years, smoking weaned 10 years ago, had consulted for LUTS not improved by alpha-blocker treatment associated with microscopic hematuria on several ECBUs without urinary tract infection, without any associated sign, the whole evolving in a context of apyrexia and conservation of the general state.
The clinical examination is unremarkable. The rectal examination shows a flexible $60 \mathrm{~g}$ prostate without a nodule. Examination of EMBs and lymph node areas is normal.

Ultrasound shows a $75 \mathrm{~g}$ prostate with $70 \mathrm{ml}$ RPM, with normal sized kidneys without abnormalities.

Abdomino-pelvic computed tomography $(01 / 24 / 2018)$ shows 2 normal kidneys with the presence of a $20 \mathrm{~mm}$ retroperitoneal tissue lesion at the lower pole of the right kidney which is enhanced with PC injection.

The PET scan (02/06/2018) shows a hypermetabolic lesion, with an SUV MAX of 4, as well as a thyroid goiter at the expense of the left lobe (Figure $1 \& 2)$.

A report was carried out (05/02/2018): ACE: 2 $\mu \mathrm{g} / \mathrm{l}$; NSE $15 \mathrm{ng} / \mathrm{ml}$; AFP $1.2 \mathrm{ng} / \mathrm{ml}$; HCG <1; Chromogranin A: $123 \mathrm{ng} / \mathrm{ml}$ (Chromogranin A down on 03/08/2018 after stopping PPI (109ng / ml)).

Faced with the possibilities of a paraganglioma or a tumor that may be an ectopic pheochromocytoma, urinary metanephrines are negative (02/09/2018). 
The biopsy seems difficult given the position of this lesion between the inferior pole of the kidney and the IVC.

The patient underwent a right lumpectomy by lobotomy (03/20/2018). Histological examination shows localized Castelman Benigne GG disease (Figure 3,4 \& 5).

The evolution turned out to be favorable, with no locoregional recurrence or distant recurrence. The follow-up is 1 year.
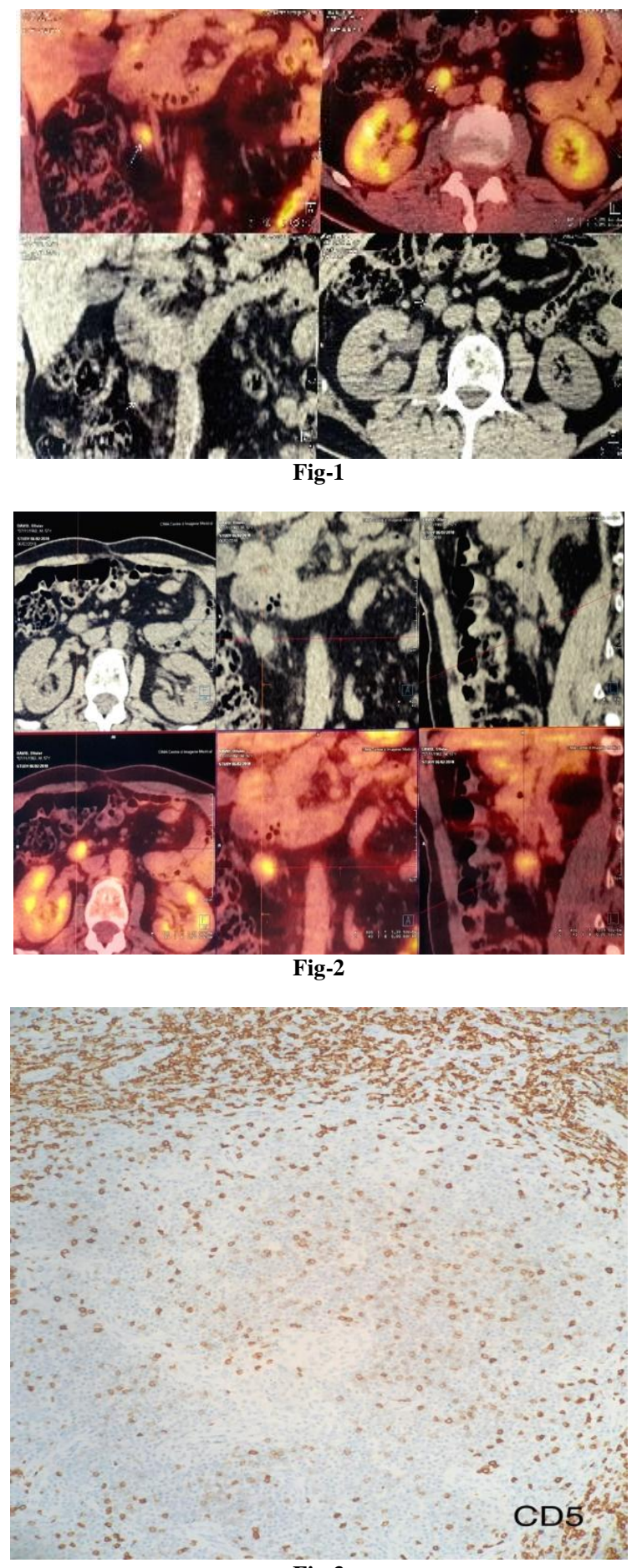

Fig-3

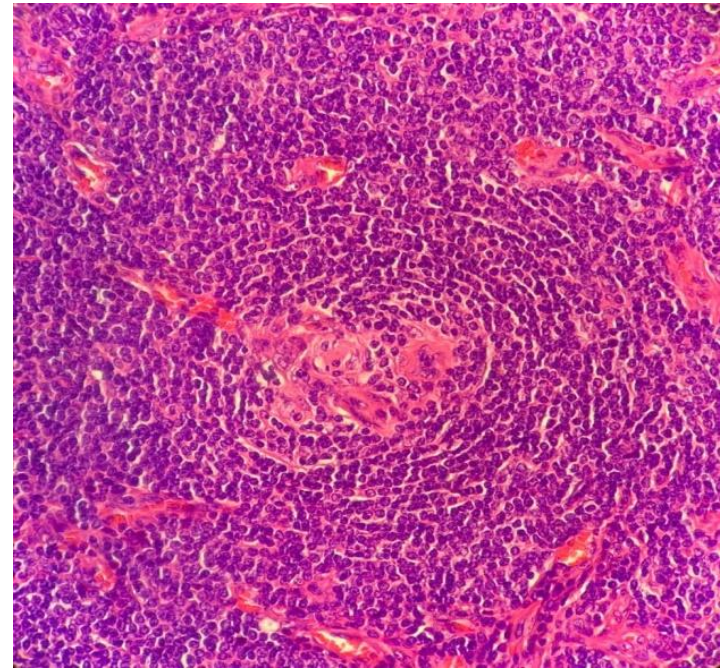

Fig-4

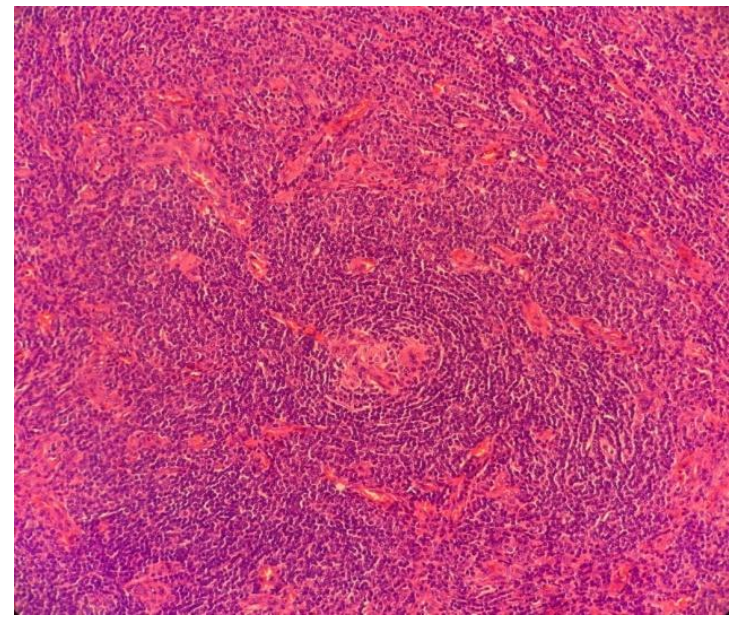

Fig-5

\section{DISCUSSION}

Castleman's disease or angiofollicular lymphoid hyperplasia is a rare condition that can be seen at any age. It affects men and women without gender predominance and was first described in 1954 [1].

The etiology of this pathology remains uncertain. However, possible causes include chronic inflammation, immunodeficiency, autoimmunity, tuberculosis, toxoplasmosis, Epstein Barr virus, infection with human herpes virus 8 (HHV8) as well as increased serum levels of interleukin 6 (IL6) [2].

Indeed, there are two clinical forms: localized unicentric form, pseudotumoral with a good prognosis; and multicentric form associated with more aggressive dysimmunity manifestations.

It is symptomatic in less than $10 \%$ of cases; revealing either by a tumor syndrome with compression of neighboring organs, or by a systemic inflammatory syndrome with hyperthermia, night sweats and deterioration of the general condition. 
Castleman's disease is easily confused with lymphoma or other solid tumors on X-ray examination. The radiological characteristics are not very specific; his diagnosis remains pathological [3]:

Three histological types have been identified in the forms not associated with the HHV-8 virus:

1. The type with hyalinized or Hyper-Vascular (HV) vascularization marked by the importance of the regression of germinal centers, vascular anomalies and anomalies of the network of follicular dendritic cells. It is the most common form of localized CD.

2. The plasma cell type marked by significant interfollicular plasmacytosis, whereas the vascular and follicular dendritic cell abnormalities are modest. It is the most common form of idiopathic multicenter CD.

3. We describe mixed or intermediate forms between $\mathrm{HV}$ and PC and in particular a hypervascular form with fibrosis observed rather in Asian patients (TAFRO syndrome).

4. The form associated with the HHV-8 virus is superimposable on the plasma cell form but is distinguished by the presence of "plasma" cells infected with HHV-8 and identifiable by an immunohistochemistry (LANA) technique.

Our observation responds to the unicentric form which is seen in 80 to $90 \%$ of cases. The multicentric form, rarer, is seen in 10 to $20 \%$ of cases corresponds to the diffusion of lymphatic involvement to multiple lymph node areas, with possible visceral extension. In this form, the clinical and biological inflammatory signs are constant $[4,5]$.

The first-line treatment for unicentric Castleman's disease is surgical excision; it generally ensures healing when it is complete. Tumor volume reduction can be done for lesions that are difficult to access, followed by monitoring or focal radiotherapy [6-9].

Treatment of multicenter Castleman's disease aims to reduce lymph node mass, treat symptoms, and reverse the inflammatory syndrome and its consequences. Different therapeutic approaches are possible and use corticosteroids, monoclonal antibodies targeting IL-6 or its receptor or even immunosuppressants [10].

For Castleman's disease associated with HHV8 , the current standard of treatment is the use of an antiB monoclonal antibody, rituximab ${ }^{\circledR}$. It is often combined with etoposide which results in rapid improvement of symptoms [10].

Treatment of the associated immune deficiency is fundamental (anti-retroviral treatment for HIV, reduction in immunosuppression during transplants).
Relapses are possible but may again be susceptible to the same treatment [10].

For our patient, the evolution turned out to be favorable, without locoregional recurrence or distant recurrence with a follow-up of 1 year.

\section{CONCLUSION}

Castleman's disease is a rare condition of uncertain cause. It poses a diagnostic and therapeutic problem with retroperitonial solid cancers, hence the need to perform a surgical excision of the lesion with anatomopathological study thus constituting a treatment in the unicentric forms.

\section{RÉFÉRENCES}

1. Castleman B, Towne VW. CASE records of the Massachusetts General Hospital weekly clinicopathological exercises: case 40011. N Engl J Med. 1954;250:26-30.

2. Casper C. The aetiology and management of Castleman disease at 50 years: translating pathophysiology to patient care. Br J Haematol. 2005;129:3-17.

3. Wang W, Medeiros LJ. Castleman disease. Surgical pathology clinics. 2019 Sep 1;12(3):84963.

4. Herrada J, Cabanillas F, Rice L, Manning J, Pugh W. The clinical behavior of localized and multicentric Castleman disease. Annals of Internal Medicine. 1998 Apr 15;128(8):657-62.

5. Peterson BA, Frizzera G. Multicentric Castleman's disease. Seminars in Oncology, 1993; 20: 636-647.

6. Bowne WB, Lewis JJ, Fillipa DA, Niesvizky R, Brooks AD, Burt ME. The management of unicentric and multicentric Castleman's disease. A report of 16 cases and a review of the literature. Cancer, 1999; 85:706-717.

7. Gheysens B, Baste JC, Midy D, Pheline P, Alessandrin JF, Parrens M, De Mascarel A. La maladie de Castleman rétropéritonéale. A propos d'une nouvelle observation. J Chir. 1994;131:492495.

8. Guillem P, Karoui M, Deroide G, Herjean M, Leteurte E, Triboulet JP. Maladie de Castleman de localisation mésentérique. Gastroenterol. Clin Biol, 2000; 24:116-120.

9. Fajgenbaum DC, Uldrick TS, Bagg A, Frank D, Wu D, Srkalovic G, Simpson D, Liu AY, Menke D, Chandrakasan S, Lechowicz MJ. International, evidence-based consensus diagnostic criteria for HHV-8-negative/idiopathic multicentric Castleman disease. Blood. 2017 Mar 23;129(12):1646-57.

10. Okamoto S. Recent advances in diagnosis and treatment of idiopathic multicentric Castleman disease. [Rinsho ketsueki] The Japanese journal of clinical hematology. 2019;60(9):1205-11. 